\title{
Fish Oil: Perspectives on a Sustainable Multi-Use Resource
}

\section{Mahmoudreza Ovissipour and Barbara Rasco*}

School of Food Science, Washington State University, Pullman, WA 99164-6376, USA

There are abundant global aquatic resources that can be economically, socially and environmentally applied as an alternative for the gradual substitution of fossil fuels, promoting sustainable development ofcarbon neutral biomass as anenergy source. Atmospheric carbon dioxide concentrations have increased from 280 $\mathrm{ppm}$ in the 1700 s to $380 \mathrm{ppm}$ in 2005 , and at a progressively higher rate each decade. Anthropogenic activities such as (1) fossil-fuel combustion and industrial processes, (2) land-use changes, mainly land clearing, are the main reasons for increased $\mathrm{CO}_{2}$ emissions and a major contributor to global warming. In addition, there are several concerns about the fossil fuels such as increasing price, decreasing the resources, civil strife in major producing countries and unstable political situations across the Middle East and North Africa make it more important to be able to provide energy from alternative sources that will not promote environmental degradation.

Terrestrial resources are not a long term viable option since this will usually require taking crop land out of food production. The use of agricultural and forest products waste materials for biodiesel production, for example, provide a source of organic compounds including cellulose, hemicelluloses, lignin, triglycerides and fatty acids but use of fishery byproducts and marine algae have found limited application to date either because of technological or logistic restrictions. Animal fat and fish oil have the potential for greater use as a non-food energy source and the use of animal fat as a source of energy is not a new technology; however the adaptability of this technology to aquatic resources has only recently attracted public interest. Using animal fat as fuel (oil lamp) backs to 15,000 years in France and at least 6000 years ago in Egypt.

Terrestrial animals processing is more efficient compared to seafood production with a fairly well developed by-products industry. Almost the $50 \%$ of the total processed seafood is the waste materials including underutilized species, bone, viscera, roe, milt, head, tongues, skin, fin, mollusc and crustacean shells, and dark muscles which are rich in protein, oil, and minerals remain following harvest and could be used for feed or fuel uses if these materials could be collected efficiently and further processed. Many of these byproducts have high value as human food such as roe, milt, and tongue. Other components, particularly minerals from marine wastes could be used as catalyst for biofuel production or for feed applications. Unfortunately, most of the byproducts are discarded or converted to low quality fish meal, fertilizer or animal feed which has less economic value than it should have. Some byproducts such as dark muscles, skin, head, and viscera are discarded or dumped in landfill or ocean which can cause several environmental issues due to the high biological and chemical oxygen demand.

Using fish to a greater extent for fuel, at least fish from the marine capture fisheries, may be problematic due to reductions in harvest, although increasing the efficiency of collection and processing of byproduct materials could overcome this issue to some extent.In 2010, China is the top ranking major fishing country in terms of quantity followed by Indonesia, India, the United States and Peru. Also, the top ten producers of farmed aquatic animals were China (36.7 million tons), India (4.6 million tons), Vietnam (2.7 million tons), Indonesia (2.3 million tons), Bangladesh (1.3 million tons), Thailand (1.4 million tons), Norway (1.0 million tons), Egypt (919,600 tons), Myanmar (850,700 tons) and the Philippines (744,700 tons) contributing $87.6 \%$ of world production by quantity. For marine harvest, anchoveta has the highest harvest volume, although harvests dropped 39\% from 2009 to 2010. It is followed by Alaska pollock, skipjack tuna, Atlantic herring and chub mackerel. Harvests of the gadiformes as a group (e.g. cods, hakes, and haddocks) have decreased by two million tons in recent years. Capture of other important commercial species groups such as tunas and shrimps have remained stable.

World wild harvest fish production is stagnant and presently stands at 148.5 million tons as of 2010. The high quality fish meal and fish oil for human consumption and animal feed, are producing from pelagic fishes such as anchovies or capelin harvested in Peru and Chile, and cod liver oil in Scandinavian countries. In 2011, the global production of fish meal and fish oil was 5,207,000 tons, and 1,072,000 tons, respectively, with by-products constituting $25 \%$ of the total fish meal production. In Alaska, annual production of fish oil is about eight million gallons. Aquaculture is both a potential source of and major buyer for fish meal and oil, using $73 \%$ of the world's production of fish meal and $71 \%$ of the oil as of 2010 and use of the oil for fuel would have to be competitive with other current uses.

One important alternative for fishery byproduct utilization is biofuel which is renewable, biodegradable, and creates less greenhouse gas emissions than fossil fuels. Realistically biodiesel could replace approximately $10 \%$ of the diesel fuel consumed within Europe and $5 \%$ in Southeast Asia. Biodiesel is sulphur free and with low aromatic hydrocarbon content while conventional diesel contains up to 500 ppm $\mathrm{SO}_{2}$ and 20 to $40 \%$ aromatic compounds. Transportation is an important contributor of the total gas emissions; hence, using biodiesel could be a key solution to reduce the urban pollution. Almost one third of the total transport generated greenhouse gas emissions is because of the diesel. Using biodiesel can decrease the $\mathrm{CO}_{2}, \mathrm{CO}$ and black smoke up to $14,17.1$ and $22.5 \%$, respectively.

Biodiesel production from vegetable oil feedstock has been well studied during the past several years. However, there are several critical issues for the biodiesel production from vegetable oil. The cost of vegetable oils could be up to $75 \%$ of the total manufacturing cost, and increases the total cost approximately 1.5 times higher than conventional diesel. Using fish oil may result in higher materials costs in most locations but having a local source of fuel, particularly in

*Corresponding author: Barbara Rasco, School of Food Science, Washington State University, Pullman, WA 99164-6376, USA, Tel: 509- 335-1858; E-mail: rasco@wsu.edu

Received February 14, 2014; Accepted February 19, 2014; Published February 27,2014

Citation: Ovissipour M, Rasco B (2014) Fish Oil: Perspectives on a Sustainable Multi-Use Resource. J Aquac Res Development 5: e109 doi:10.4172/2155 9546.1000e109

Copyright: (C) 2014 Ovissipour M, et al. This is an open-access article distributed under the terms of the Creative Commons Attribution License, which permits unrestricted use, distribution, and reproduction in any medium, provided the original author and source are credited. 
underserved and remote areas may be viable.

There are different processes to produce biofuel from a lipid feedstock including esterification/transesterification reactions which require a catalyst, pyrolysis, a form of heating, micro-emulsion and direct use or blending. Much research has been conducted on the use of triglycerides and waste oils as feedstock to produce biodiesel using esterification or transesterificationreactions, however, several factors inhibit the wider use of this technology. For example, when the raw materials are comprised primarily of triglycerides, variation in solids content, differing acid index, susceptibility to lipid oxidation and soap formation resulting from reaction of free fatty acids and catalysts affect yield and quality of biodiesel. The production facility for biodiesel remains relatively sophisticated and solvents are commonly used for oil recovery. The critical point in using the fish oil as biofuel is free fatty acid (FFA) formation due to the high polyunsaturated acids (PUFA) which are prone to lipolysis and oxidation. In general, the transesterification reaction is carried out in methanol with alkaline catalysis. If the FFA in the feedstock is more than $0.5 \%$, soap could be formed and decreases the efficiency of the catalyst. Hence, the FFA should be removed by refining which can increase the cost.

Due to this, some researchers have recently focused more on a pyrolysis process to produce biofuel from triglycerides based feedstock. Pyrolysis permits conversion of a feedstock directly to biofuel with a complex mixture of hydrocarbons being formed. However, this technology has not been well established and much work is needed on process optimization, product analysis, scale up and economic feasibility.

There are several parameters which influence the cost of biodiesel from fish byproducts, mainly, length and range of harvesting season, resource availability, harvesting method, species, byproducts chemical properties, fish processing method, and logistics. These factors can be categorized in three main groups:

- Materials collection: Byproduct collection is estimated at $1 \%$ of the total cost. Byproducts need to be stabilized either chemically or by refrigeration so that the peroxidase activity does not increase the FFA of the viscera. Other byproducts head, bone, and skin could separately be recovered for other markets.

- Oil extraction: There are several ways to extract the oil fishery byproducts.

$\checkmark$ Ensiling or acidification by decreasing the $\mathrm{pH}$ to 3.5-4.0 causing protein autolysis to protein hydrolysates and a separate oil fraction. This method must be carefully controlled so that the level of soluble proteins,small peptides and free amino acids are not too high. If this process is carefully controlled, suitable animal feed components and organic fertilizers can be obtained. At lowambient temperature, the hydrolysis process can take at least one week, and lipid oxidation could occur reducing the quality of the oil along with the ability to recover it.

$\checkmark$ Fish meal and oil can also be made by a thermal process $\left(95-100^{\circ} \mathrm{C}\right.$ for 15 to $20 \mathrm{~min}$ ) with the recovered material added as a component to fish meal. Fish oil is a co-product. In Alaska, alone, 25,000 kg of wastes are converting to fish meal and fish oil per day by this method.

$\checkmark$ Enzymatic hydrolysis is conducted by adding commercially available enzymes to the mixture to high protein byproducts yielding protein hydrolysates with different degrees of hydrolysis and molecular weight profiles designed for specific applications such as: microbial media, calf milk replacer, and protein supplements for human nutrition including sport beverages, and infant formula. These hydrolysates can aid in water retention during the canning of muscle foods. In this method, fish oil is a co-product and could be used for different purposes. Enzymatic hydrolysis has several advantages. It is a controllable process conducted at mild temperatures $\left(50^{\circ} \mathrm{C}\right)$ with a short process time $(1$ to $3 \mathrm{~h}$ ). Compared to acid hydrolysis, there is less solid residue after processing. Less sophisticated equipment is required compared to fish meal production and the set-up is easily constructed and operated. The oil yield from enzymatic hydrolysis using commercial enzymes is approximately twice as high as from autolysis processes. The quality of the oil after separating is higher than by other methods due to the shorter time and reduced amount of heat.

- Byproducts storage: The microbial load of fishery by products is often high and susceptible compounds such as protein can be easily degraded, mechanical damage to the byproducts and endogenousenzyme activity makecold chain management critical. Even during frozen storage, enzyme can remain active and lipid oxidationcan continue. Hence, extracting the oil from byproducts should be performed without delay.

Recently, Taku Renewable Resources, Inc. (Fishermen's Daughters Ecofuels) in 2010, conducted a survey feasibility study in Alaska for biofuel production from fish oil extracted from fish byproducts. Also, they introduced two other active plants, including Aquafinca in Honduras, and VTT Technical Research Center in Finland. Taku Renewable Resources, Inc. found seven sites in Juneau, Alaska, USA which together produce approximately $6000 \mathrm{mt}$ of fisheries byproducts. More than $80 \%$ of this byproduct is wild salmon wastes (heads, skins, frames and viscera) and produced from June through September, with a peak in July and August, all of which could be converted to products of higher value.

There is a great potential for biodiesel production from fish byproducts, particularly in Asia, and USA, providing an alternative use for fish byproducts, and increase the profitability of a fishery for rural people in coastal communities and providing them with an alternative and potentially relatively cheap source of fuel. For example, in USA, Hawaii and Alaska pay much higher prices for petrochemical fuels with recent pricing of $\$ 3.67 /$ gallon compared to USA average price of $\$ 3.20$ / gallon. Hawaii and Alaska are both major producers of the aquatic products in USA, and have strong rural and coastal cultures. There are several advantages for increasing utilization of fish byproducts in these states, including value added products such as fish protein hydrolysates for different application, the use of fish oil for fuel directly or via conversion to biodiesel. Similarly, a concerted effort should be made to improve the collection and utility of fishery byproducts at harvest and production locations around the world. Even if the quantity is relatively small, much can be done with these materials to increase their value for food, feed and potentially fuel uses. 